\title{
Metastatic Malignant Melanoma to the Bladder: A Case Series
}

\author{
Eric S. Wisenbaugh Melissa L. Stanton Gwen M. Grimsby Mark D. Tyson Erik P. Castle \\ Mayo Clinic Arizona, Phoenix, Ariz., USA
}

\section{Key Words}

Bladder • Bladder tumor • Hematuria • Metastasis •

Malignant melanoma

\begin{abstract}
Background: Metastatic melanoma to the bladder is rarely reported, and the role of surgery is still largely unknown. We review 4 such cases and highlight their management and outcomes. We also review the relevant literature. Methods: The Mayo Clinic tumor database was searched and 4 such cases were found. Results: All 4 patients were treated locally with transurethral resection. The only patient who had a solitary metastasis did relatively well, having no evidence of disease 10 months after his presentation, while the other 3 died within 6 months. The literature highlights various approaches to management, but there is no definitive evidence that radical cystectomy offers any benefit over transurethral resection. Conclusion: Resection may improve survival in the setting of a solitary metastasis, but there is no evidence that radical cystectomy offers any benefit over local resection. With diffuse disease, however, resection is likely only beneficial for treatment of hematuria.
\end{abstract}

Copyright $\odot 2012$ S. Karger AG, Basel

\section{KARGER}

Fax +41613061234

E-Mail karger@karger.ch

www.karger.com
(C) 2012 S. Karger AG, Basel

1015-9770/12/0061-0053\$26.00/0

Accessible online at:

www.karger.com/cur

\section{Introduction}

Malignant melanoma may metastasize anywhere in the human body, however metastases to the bladder is a rare clinical diagnosis, and thus published reports are scarce. A recent review found less than 10 cases reported in the English literature over the last 30 years [1]. A review of every case reported prior to 1966 found only 23 [2]. The largest single series presented to date involves only 3 patients [3].

These findings, however, should not imply that melanoma does not spread to the bladder. Autopsy series have shown $18 \%$ of patients with distant metastatic melanoma had disease involving the bladder which indicates that the large majority of these tumors remain asymptomatic [4]. We present 4 patients, the largest single case series to date, who were diagnosed with malignant melanoma that had metastasized to the bladder, and review their management.

\section{Materials and Methods}

We searched the entire tumor database of Mayo Clinic for any diagnosis of 'melanoma' within the genitourinary tract. Four cases with existing records of melanoma within the bladder were found and their charts were examined. We searched PubMed using the terms 'bladder' and 'melanoma' for any relevant English literature. 


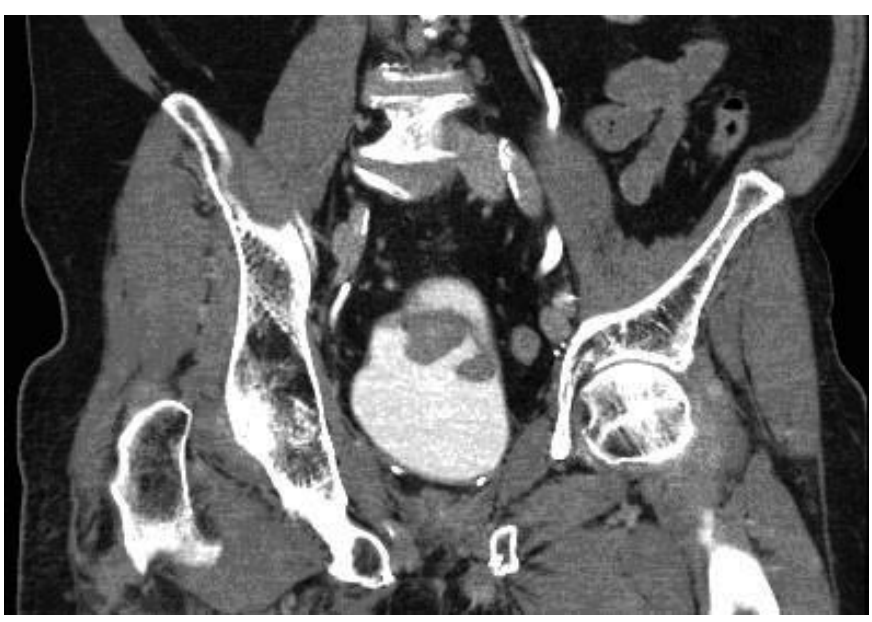

Fig. 1. Sagittal reconstruction of delayed CT of the pelvis shows ill-defined lobular hypodensities in the bladder.

Case 1

An 81-year-old male presented with microscopic hematuria, urinary frequency and hesitancy. His past history was significant for having undergone a wide local excision of a superficial spreading melanoma on his right shoulder 2 years prior. Margins at the time were negative, but his sentinel cervical lymph node was positive. He underwent a right selective cervical neck dissection and all 33 lymph nodes were negative.

Computed tomography (CT) showed ill-defined lobular hypodensities in the bladder (fig. 1). Cystoscopy revealed 2 large polypoid lesions, which was later confirmed as metastatic malignant melanoma. Extensive imaging revealed no other areas of metastasis.

The oncology team determined that he could not tolerate adjuvant interferon given his age and comorbidities. Radical cystectomy was offered, but the patient opted for surveillance. At time of last follow-up, 10 months after his microscopic hematuria was found, he had no evidence of recurrent disease as demonstrated by whole body positron emission tomography scan.

\section{Case 2}

An 84-year-old male presented with anemia and gastrointestinal bleeding. His past history was pertinent for 3 melanomatous skin cancers 15 to 18 years prior that had all been treated with local excision. CT enterography noted an incidental lobulated bladder mass (fig. 2), as well as a cavitated mass within the pelvis that communicated with the small bowel.

The patient had no urinary complaints, but was found to have microscopic hematuria and a urinary tract infection. Transurethral resection of his bladder mass revealed metastatic melanoma with submucosal invasion. A small bowel resection was performed for a $7 \mathrm{~cm}$ metastasis which extended into the serosal surface and mesenteric vein. His postoperative course was complicated by a small bowel intussusception requiring a second resection, which

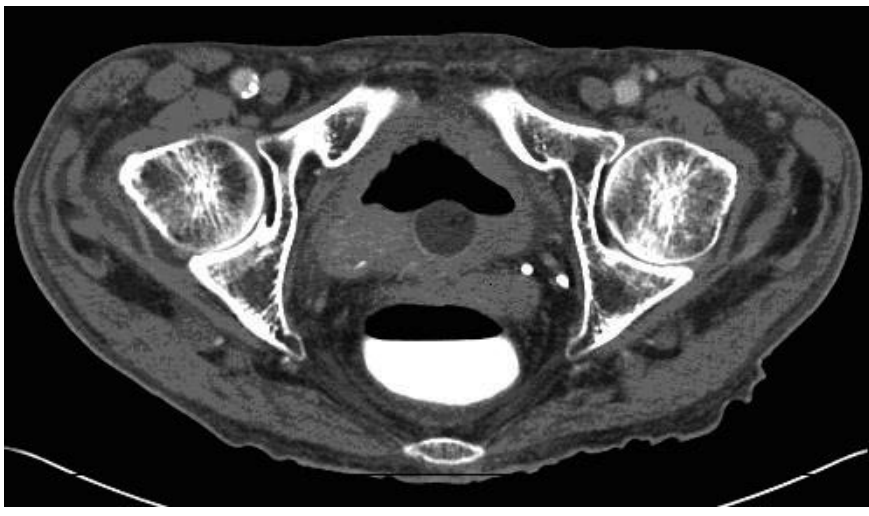

Fig. 2. Axial image of CT enterography showing an incidental lobulated bladder mass adjacent to the balloon of the Foley catheter.

again revealed metastatic melanoma. Adjuvant chemotherapy was not deemed appropriate given his age, comorbidities and extent of metastatic disease. He was referred to palliative care and died 4 months after presentation.

\section{Case 3}

An 85-year-old male presented to the urology clinic complaining of gross hematuria. He had a history of malignant melanoma of his right shoulder 19 months prior and had a subsequent wide local excision and axillary lymph node dissection which confirmed metastatic disease in 8 of 24 lymph nodes, and was treated with adjuvant radiation therapy.

Cystoscopy was performed and 2 separate darkly pigmented tumors were visualized and resected. Pathology confirmed metastatic malignant melanoma. Positron emission tomography scan reported multiple areas consistent with metastatic disease in abdominal lymph nodes, stomach, lungs and bladder. The patient chose not to pursue any additional treatment, and was transferred to hospice care where he died within 4 months of his bladder biopsy.

\section{Case 4}

A 62-year-old female with known metastatic melanoma presented to urology clinic for management of a bladder mass found on CT. She had a history of ocular melanoma treated by enucleation, and presented 10 years later with a left neck mass. Further evaluation found multiple distant metastases and she was started on chemotherapy. She continued to have progressive disease and a new bladder mass was found. Local therapy was initially deferred as she was asymptomatic from a urologic standpoint. Her disease continued to progress, and she later developed symptomatic hematuria. Resection of the bladder mass was undertaken and final pathology confirmed metastatic melanoma. Her hematuria resolved, but she failed to respond to any further chemotherapy, 
Table 1. Four cases of metastatic melanoma to the bladder

\begin{tabular}{|c|c|c|c|c|c|c|}
\hline Case & $\begin{array}{l}\text { Years from pri- } \\
\text { mary to bladder } \\
\text { metastases }\end{array}$ & $\begin{array}{l}\text { Known active } \\
\text { metastases prior } \\
\text { to diagnosis of } \\
\text { bladder tumor }\end{array}$ & $\begin{array}{l}\text { Urologic presenta- } \\
\text { tion }\end{array}$ & Survival from presentation & Treatment & Solitary metastasis \\
\hline 1 & 2.4 & no & $\begin{array}{l}\text { microhematuria, fre- } \\
\text { quency, hesitancy }\end{array}$ & NED at 10 months & TURBT & yes \\
\hline 2 & 18 & no & $\begin{array}{l}\text { incidental finding } \\
\text { on CT for gastroin- } \\
\text { testinal bleed }\end{array}$ & 4 months & TURBT & no \\
\hline 3 & 1.5 & no & gross hematuria & 4 months & TURBT & no \\
\hline 4 & 10 & yes & $\begin{array}{l}\text { incidental on re- } \\
\text { staging CT }\end{array}$ & 5 months & TURBT & no \\
\hline
\end{tabular}

$\mathrm{NED}=$ No evidence of disease TURBT $=$ transurethral resection of bladder tumor .

and she died of her disease just over 5 months after her bladder tumor was found.

\section{Discussion}

As metastatic melanoma to the bladder is rarely diagnosed during a patient's lifetime, little is known regarding the effectiveness of local treatment. Of the 4 patients in this series, all underwent transurethral resection (table 1). Three of these were done primarily for diagnostic purposes, while the last one was palliative. The prognosis of metastatic melanoma in general is dismal, with a median survival of only 6 to 8 months [5]. The 3 of our patients who had multiple metastases all died within 6 months of the diagnosis of their bladder lesion. This is consistent with Walsh's review, where 10 of the 14 patients who had mortality data available died within 6 months of their bladder surgery. However, the patient in our series who had a solitary bladder metastasis had no evidence of recurrence at 10 months.

There is considerable debate as to the role of surgery in this setting. Given that survival for metastatic melanoma is dependent on the resectability and number of metastases, radical cystectomy has been used in patients with solitary metastasis [1]. We found no definitive evidence, however, that radical cystectomy is superior to local resection, and some authors believe that the presence of bladder metastasis is a manifestation of widespread disease and precludes exonerative surgery [6]. Traditionally, transurethral resection has been advocated for palliation only. However, the objective response rates that have been seen in giving high-dose interlueken- 2 for treatment of metastatic melanoma has allowed some to propose that transurethral resection may be beneficial in patients with hematuria to optimize them for immunotherapy, especially given that hematuria would otherwise preclude them [5]. Gerridzen et al. [7] managed a patient with a solitary bladder metastasis with transurethral resection and surveillance cystoscopy and found no evidence of local recurrence 4 years after initial resection. This particular patient died of pulmonary metastases without any evidence of local recurrence.

\section{Conclusion}

Metastatic malignant melanoma to the bladder is often a part of a diffuse metastatic process with a dismal prognosis, and the role of surgery is not clearly defined. Resection may add a survival benefit in the setting of a solitary metastasis, but there is no definitive evidence that radical cystectomy offers any benefit over local resection. In the setting of known diffuse disease, however, local resection is likely only beneficial for palliation or to allow for systemic immunotherapy. 


\section{References}

$\checkmark 1$ Efesoy O, Cayan S: Bladder metastasis of malignant melanoma: A case report and review of literature. Med Oncol 2011;28(suppl 1):s667-669.

$\checkmark 2$ Walsh EJ, Ockuly EA, Ockuly EF, Ockuly $\mathrm{JJ}$ : Treatment of metastatic melanoma of the bladder. J Urol 1966;96:472-478.

$>3$ Meyer JE: Metastatic melanoma of the urinary bladder. Cancer 1974;34:1822-1824. $\checkmark 4$ Dasgupta T, Brasfield R: Metastatic melanoma. A clinicopathological study. Cancer 1964;17:1323-1339.

5 Lee CS, Komenaka IK, Hurst-Wicker KS, Deraffele G, Mitcham J, Kaufman HL: Management of metastatic malignant melanoma of the bladder. Urology 2003;62:351.
6 Weinstock BI, Willscher MK, Novicki DE: Importance of urinary tract investigation in metastatic malignant melanoma. Urology 1977;10:547-549.

Gerridzen RG, Thijssen AM: Long-term survival with malignant melanoma metastatic to the bladder. Can J Urol 1994;1:53-54. 